\title{
Incorporating flexibility options into distribution grid reinforcement planning: A
} techno-economic framework approach

Klyapovskiy, Sergey; You, Shi; Michiorri, Andrea; Kariniotakis, George; Bindner, Henrik W.

Published in:

Applied Energy

Link to article, DOI:

10.1016/j.apenergy.2019.113662

Publication date:

2019

Document Version

Peer reviewed version

Link back to DTU Orbit

Citation (APA):

Klyapovskiy, S., You, S., Michiorri, A., Kariniotakis, G., \& Bindner, H. W. (2019). Incorporating flexibility options into distribution grid reinforcement planning: A techno-economic framework approach. Applied Energy, 254, [113662]. https://doi.org/10.1016/j.apenergy.2019.113662

\section{General rights}

Copyright and moral rights for the publications made accessible in the public portal are retained by the authors and/or other copyright owners and it is a condition of accessing publications that users recognise and abide by the legal requirements associated with these rights.

- Users may download and print one copy of any publication from the public portal for the purpose of private study or research.

- You may not further distribute the material or use it for any profit-making activity or commercial gain

- You may freely distribute the URL identifying the publication in the public portal 


\title{
Incorporating flexibility options into distribution grid reinforcement planning: A techno-economic framework approach
}

\author{
Sergey Klyapovskiya, Shi You ${ }^{\mathrm{a}, *}$, Andrea Michiorri ${ }^{\mathrm{b}}$, George Kariniotakis ${ }^{\mathrm{b}}$, \\ Henrik W. Bindner ${ }^{a}$, \\ ${ }^{a}$ Center for Electric Power and Energy (CEE) \\ Technical University of Denmark (DTU) \\ 2800 Kgs. Lyngby, Denmark \\ ${ }^{b}$ Centre for Processes, Renewable Energies and Energy Systems (PERSEE) \\ MINES ParisTech \\ 06904 Sophia Antipolis, France
}

\begin{abstract}
Distributed energy resources (DER) and new types of consumer equipment create many challenges for the distribution system operators (DSOs). Power congestions that can potentially be created during normal or contingency situations will lead to increased investments into grid reinforcement. An alternative solution is to use the flexibility provided by the local resources in the grid. In this paper value of flexibility $(\mathrm{VoF})$ is used as an indicator that can be utilized by the DSO to compare it against costs of the different active elements (AEs) providing flexibility services (FSs). The paper proposes flexibility characterization framework that allows to generalize the process of the cost estimations of any $\mathrm{AE}$ by using combinations of cost functions. A case study based on an actual distribution grid is provided to demonstrate
\end{abstract}

\footnotetext{
* Corresponding author

Email address: sy@elektro.dtu.dk (Shi You )
} 
the potential application of the framework. Results show that by comparing VoF and total cost of the flexibility the most cost-efficient solution could be found.

Keywords: Active distribution network, flexibility characterization

framework, active elements, flexibility services.

\section{Nomenclature}

\section{Abbreviations}

ADN active distribution network

AE active element

BESS battery energy storage system

CAPEX capital expenditures

CB circuit-breaker

CE congestion event

DER distributed energy resources

DG distributed generation

DLR dynamic line rating

DR demand response

DSO distribution system operator

ENS energy not supplied 
ESS energy storage system

EV electric vehicle

FS flexibility service

HP heat pump

LT lifetime

MCC maximum carrying capacity

MS main substation

NPV net present value

OLTC on-load tap changer

OPEX operational expenditures

$\mathrm{RE}$ reconfiguration

SW switching

TL tie-line

TOTEX total expenditures

VoF value of flexibility

\section{Parameters}

$B F, B F_{\text {flex }}$ benefits of postponing the reinforcement and benefits of using AEs, 
$C$ CAPEX or OPEX cost,

$C\left(F_{O 1}\right), C\left(F_{O 2}\right), C\left(F_{O 3}\right), C\left(F_{O 4}\right)$ OPEX from using AE, determined by the cost functions,

$C 1, C 2$ CAPEX parameters of the framework,

$C_{A E, f e a t}, C_{A E, M \& L}$ additional cost due to the unique features of an $\mathrm{AE}$ and cost of maintenance and losses caused by an $\mathrm{AE}$,

$C_{A E}, A_{A E}$ self-cost and additional expenses caused by installation of an $\mathrm{AE}$,

$C_{c o m p, M \& L}$ cost of the maintenance and losses for the component,

$C_{\text {comp }}, I C_{\text {comp }}, A_{\text {comp }}$ self-cost, installation cost and additional expenses caused by the installation of the component,

$C_{\text {conv }, C A P E X}, C_{\text {conv }, \text { OPEX }}, C_{\text {conv }, T O T E X}$ CAPEX, OPEX, TOTEX of the conventional planning solution,

$[€]$

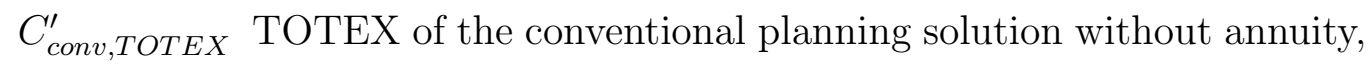

$C_{E N S}$ cost per unit of ENS, $[€ / \mathrm{kVAh}]$

$C_{f l e x, C A P E X}, C_{f l e x, O P E X}, C_{f l e x, T O T E X}$ CAPEX, OPEX, TOTEX of the flexibility planning solution,

$C_{\text {TOTEX }}$ TOTEX of a planning solution,

$[€]$

$D_{\text {flex,end }}$ ending point of AE's usage during CE, 
$D_{\text {flex }}$ duration of using an AE,

$d r \quad$ discount or interest rate,

$E_{E N S}$ total amount of ENS,

$E_{\text {flex }}$ total requested energy from the flexibility,

$G 1, G 2, G 3$ general parameters of the framework,

$h_{\text {comp }}$ number of hours the component is in operation,

$K \quad$ total number of AEs used for providing flexibility,

L short-term overloading coefficient,

$L T_{\text {comp }}$ component's LT,

$N C$ total number of components,

$N O_{\text {flex }}$ total number of times flexibility from an AE is used,

pl planning horizon,

$R O C_{\text {flex }}$ rate-of-change of requested capacity from an $\mathrm{AE}$,

$S_{\text {cable }, M C C}$ cable's MCC,

$S_{\text {cable,rated }}$ cable's rated apparent power,

$S_{d c, c o n v}, S_{d c, f l e x}$ dimensioning criteria for the component in the conventional and flexibility planning, 
$S_{\text {est,max }, N 1, y}, S_{\text {est,max,peak }, N 1}$ estimated peak power demand during N-1 at the year $y$ and during the whole planning horizon $p l$,

$S_{\text {est }}$ estimated worst case power demand for specific operation mode (e.g. normal operation, $\mathrm{N}-1$, etc.),

$S_{\text {flex }}, S_{\text {flex,mean }}$ capacity and mean capacity requested from an AE during $\mathrm{CE}$,

$S_{\text {target }}$ target peak power limit maintained throughout the planning horizon,

\section{Subscripts}

$i \quad i$ th $\mathrm{CE}$

$k \quad k$ th $\mathrm{AE}$

$n \quad n$th individual distribution network component: cable, transformer, etc.

P\% percentile

$S C \quad S C$ th scenario

$y \quad y$ th year

\section{Appendix parameters}

$\alpha \quad$ attainment factor,

$\Delta L T_{\text {cable }}^{\prime}, \Delta L T_{\text {cable }}$ reduction in cable's LT due to a CE with $T_{\text {cable, }, \text { mean }}$ and reduction referred to $T_{\text {cable,rated }}$, 
$\Delta T$ difference of temperatures,

$\delta_{\theta}, \delta_{T}$ soil hydraulic and soil thermal diffusivity,

$\left[m^{2} / s\right]$

$\lambda_{1}, \lambda_{2}$ ratios between losses in the metal sheaths of the cable and its total losses,

$\rho_{T} \quad$ soil thermal resistivity,

$\left[m^{\circ} \mathrm{C} / W\right]$

$\sigma_{S, d r y}$ dry-soil density,

$\left[\mathrm{kg} / \mathrm{m}^{3}\right]$

$\theta \quad$ moisture content,

$[-]$

$B$ degradation process coefficient,

$C_{\text {cable,total }}$ total cost of the cable,

$C_{L T_{\text {cable }}}$ cost of an hour of cable's LT,

$C_{S T}$ soil specific heat, $\left[W s / k g^{\circ} \mathrm{C}\right]$

$\cos \phi$ power factor,

$I_{\text {cable }}$ DLR of the cable,

j number of conductors in the cable,

$k_{\theta} \quad$ soil hydraulic conductivity,

$L T_{\text {cable }, D_{\text {flex }, i, s t a r t}}^{\prime}$ cable's LT at the start of $i$ th CE with $T_{\text {cable,i,mean }}$

$L T_{\text {cable,rated }}$ cable's LT at rated conditions,

$N \quad$ soil composition, 
nc number of conductors in the cable,

$q_{d} \quad$ dielectric loss, $\quad[\mathrm{W} / \mathrm{m}]$

$r \quad$ resistance of the conductor, $\quad[\Omega / m]$

$R_{T, 1}, R_{T, 2}, R_{T, 3}$ thermal resistance of cable's insulating layers, $\quad\left[m^{\circ} \mathrm{C} / \mathrm{W}\right]$

$R_{T} \quad$ soil thermal resistance, $\quad\left[m^{\circ} \mathrm{C} / W\right]$

$T$ temperature ratio, $\quad\left[1 /{ }^{\circ} \mathrm{C}\right]$

$T_{\text {cable }}, T_{\text {cable,rated }}, T_{\text {cable,i,mean }}$ cable's current, rated and mean temperature,

$T_{\text {internal }}, T_{\text {external }}$ temperatures of internal and external parts of the cable,

$T_{S} \quad$ soil temperature,

z soil layer,

$[\mathrm{cm}]$

\section{Introduction}

The intensifying efforts to reduce $\mathrm{CO}_{2}$ emissions and increase energy efficiency are bringing large number of distributed energy resources (DER), such as distributed generation (DG) $[1,2]$, energy storage systems (ESS) $[3,4,5]$ and new types of consumer devices like heat pumps (HPs) [6] and electric vehicles $(\mathrm{EVs})[7,8]$ to the distribution grids. The presence of these new components is changing the way distribution networks are operated. The electric power congestions $[9,10]$ or out-of-range voltages [11] that could be 
predicted in the previously passive networks now appear with a very short warning, requiring immediate actions.

In order to make the distribution networks more flexible and resilient towards demand profiles with high uncertainties and rapid variations, one of the most prominent solution for the distribution system operator (DSO) is to use flexibility [12] provided by the consumers or grid's components, known as active elements (AEs) $[13,14]$. Devices like HPs, EVs, ESS or even circuit-breakers (CBs) and transformers with on-load tap changer (OLTC) can be treated as AEs. The services they offer to the system are flexibility services (FSs) [15], since they allow the distribution system to better adapt to the current power demand situation and potentially evolve into an active distribution network (ADN) [16]. Long-term planning of the distribution networks, which before was considered almost independent of the system's daily operation, will become deeply intertwined with the operational planning, if the DSO chooses to utilize FSs [17, 18, 19].

Different AEs possess different characteristics and can be operated in various ways, while still providing the same FSs, like voltage regulation or peak reduction. Therefore distribution grid planners could potentially face the situations, where there is a need to choose between different AEs to achieve the same planning objective. In order to do that, AEs should be compared on the same basis. From the DSO perspective, such common ground in most of the cases is the cost of implementing the solution.

In most of the cases, FSs from AEs, that are used to solve distribution network problems are alternatives to conventional solutions, such as grid reinforcement, load curtailment, installation of voltage correction equipment, 
etc. The value of flexibility ( $\mathrm{VoF}$ ) is the maximum cost that the DSO is ready to pay for the FSs and is determined for each case individually. If the cost of using AEs exceeds the VoF, contracting the corresponding FSs will not be economically viable for the DSO.

The paper proposes a flexibility characterization framework that provides a generic approach to the cost estimation of typical AEs, while taking into account AEs' distinctive features. Quantification of the benefits and expenses from each AE through the framework will enable the comparison between different AEs and conventional solution and help the distribution planner in the related decision-making process.

The paper is structured as follows: Section II contains the state-of-theart concerning typical grid issues, quantification of the FSs, description of AEs used in the paper and their cost estimation. Four types of AEs/FSs are considered: demand response (DR), battery energy storage system (BESS), reconfiguration (RE) and dynamic line rating (DLR). Section III describes the methodology for determining the VoF. The general description of the flexibility characterization framework is given in Section IV. Section V presents the case study highlighting the potential application of the proposed framework, the results of which are shown in Section VI. Finally, conclusions are drawn in Section VII.

\section{State-of-the-art}

\subsection{Distribution grid issues}

AEs could provide flexibility, that can be used by the DSO to solve issues in the distribution grid. 
The most common issues at the distribution level are power congestions and out-of-range voltages [20, 21]. The out-of-range voltages could be either under- or overvoltages caused by various reasons, such as voltage drop, DGs (e.g. PV panels), motor start-ups, etc. Power congestion occur when the power flowing through a grid component exceeds its maximum carrying capacity (MCC), thus blocking a part of the network. Power congestion issues will be used as an example throughout this paper.

Typically, distribution grid components, such as transformers and cables allow short-term overloading $[22,23]$ without jeopardizing the system performance, which is used by the DSOs. That is why from the DSO's experience congestions are more likely to occur during contingency situations, such as $\mathrm{N}-1$ [24]. N-1 contingency is a system state, where one of the grid's components is out of operation due to a fault or a failure. To minimize the loss of load in $\mathrm{N}-1$, some of the remaining grid components will have to accommodate the increased power flows. With the increasing number of consumer devices with the cyclic operation modes (HPs, electric heaters, EVs, etc.), it could be expected to have power congestions even in the normal operation, if a large number of such devices are to turn on simultaneously.

Planning horizons used by most of the DSOs lie within 10-20 years long-term planning. However, estimation of the power consumption and parameters of the potential congestion events (CEs) requires high accuracy forecasting, which is problematic to achieve within a long time range. To be able to utilize the benefits provided by the FSs of AEs more efficiently, the planning horizons could potentially be reduced to a medium-term range (ca. 5 years). 


\subsection{Quantification of FSs}

Before a DSO can use FSs from AEs in planning, the amounts of available FSs should be properly quantified. In [25] the data-driven approach is suggested to estimate the amount of FSs obtained from a HP. By analyzing the data from the two test trials, the amounts of FSs provided in response to different tariff schemes are mapped and generalized with results applicable to the other HP systems. Similar approaches based on the data from smart grid projects are presented in [26, 27]. The dynamic flexibility function is discussed in [28]. The flexibility function shows the response of a smart building to a penalty signal like price or $\mathrm{CO}_{2}$ level. The characteristics of such a function could be used for the flexibility quantification. The probabilistic methodology involving clustering techniques is described in [29]. First, all consumers are divided into flexible and non-flexible clusters. Then the probability distribution of non-flexible consumers is built. By

comparing it to the power consumption patterns of flexible consumers, the amounts of potential flexibility could be quantified. Optimization algorithms for node flexibility estimation are shown in $[30,31]$. The node flexibility is defined as a relation between the generation and consumption at each node. The objective function attempts to balance each node by providing flexibility from different devices without violating their operational constraints. The methodology could be applied to increase the penetration of DER. Finally, [32] proposes the two-step optimization model to quantify the flexibility of power-to-heat systems. The flexibility is quantified based on how much extra power production could be absorbed by the system. 


\subsection{Cost estimation of AEs}

In order to obtain the most cost-efficient planning solution, DSO has to compare different planning alternatives such as traditional reinforcement and using FSs from AEs. A comprehensive review of planning algorithms involving AEs could be found in [33].

Cost estimation of AEs is based on an understanding of what factors form the final cost and allow the DSO to decide whether it is economically viable to use AEs in planning. The literature review of the cost models for DR, BESS, RE and DLR is given below.

\subsection{1. $D R$}

Consumer devices are typically turned on based on the user's necessity or convenience. In the case of the latter, it is possible to postpone the moment when the device starts to operate. The change in the device's operational pattern caused by an external signal from the DSO or an aggregator is called DR. DR is an FS that can be provided by a wide range of electric devices (EVs, HPs, electric heaters, electric boilers, lighting, etc.).

[34] shows the DR cost model based on the supply-demand curves made by an aggregator. [35] describes how the capacity of the DR FSs is changing following the corresponding change in price signal. The change depends on the self- and cross-elasticity coefficients of each type of DR. Calculating the bid price of the DR by taking users' comfort level into account is described in [36]. In [37] stochastic mix-integer optimization algorithm is proposed to optimize the cost of acquiring DR FSs for an aggregator. [38, 39, 40] show the cost models based on the fixed incentives, average or dynamic pricing. More examples of the methodologies for DR modelling are given in [41, 42, 43]. 


\subsection{2. $B E S S$}

BESS is a device for storing electrical energy, which can be used at a later point in time. From the DSO's perspective, BESS could be considered as a local generator, able to provide power to the nearby electrical loads during the CEs in the distribution networks, thus potentially alleviating components' overloading. BESS is an AE, typically owned by an independent party (e.g. aggregator) due to the unbundling rules in the power systems [44].

[45] describes the BESS cost model based on the levelized cost of storage. The model estimates both capital (CAPEX) and operational (OPEX) expenditures of using BESS. The cost of recharging cycles that are diminishing the BESS resource is included in the OPEX estimation. In [46] the detailed analysis of the BESS CAPEX that consists of storage unit cost, power conversion system and inefficiency factor is given. Inefficiency factor represents a relation between the rated and actual energy that could be extracted from the BESS. OPEX model of the BESS is shown in [47]. The model is split into an electrical part, where the state of charge is determined and a degradation part which estimates the reduction of a unit's lifetime (LT). Other cost models for the BESS are described in [48, 49, 50, 51, 52, 53].

\subsection{3. $R E$}

Process of changing system topology via altering its power supply routes is called RE. By using RE in the distribution grid, it is possible to shift the electrical load from the congested part of the network to the part with the spare capacity, thus ensuring that all electrical customers are provided with power, and system itself is not in jeopardy. RE is a FS provided by the CBs. Since CBs are an integral part of the distribution networks, CBs are 
the example of utility-owned AEs.

[54] determines the cost of RE via the cost of switchings (SWs). The model is further expanded in [55] by adding the CB's operation time to the number of SWs. [56, 57, 58, 59] present similar cost models for utilizing RE in planning.

\subsubsection{DLR}

In a traditional operation of distribution networks, the power ratings of overhead lines and cables are considered as fixed values independent of the external conditions. However, the exact MCCs of the lines are constantly changing and determined by the ability to dissipate the heat created by an electric current. Dynamically changing MCC based on the external conditions is referred to as DLR. By applying DLR in the ADN, a larger degree of overloading could be allowed, thus potentially eliminating CEs. DLR is a FS provided by the lines (overhead or cables), which are utility-owned AEs.

[60] describes the methodology for identifying the benefits and costs of using DLR. The cost is the cost of sensors (e.g. for soil temperature) needed to enable DLR, while the benefits are the amounts of extra energy that could flow through the cable. The DLR cost model presented in [61] shows how adding the forecast of DLR capabilities to the real-time measurements might increase the value of the DLR FSs. The degradation model of the cables under different loading conditions is given in [62]. More DLR cost models could be found in $[63,64,65,66]$.

The majority of the existing literature regarding the cost estimation and quantification of AEs is focusing on a specific technology under the specific conditions. To facilitate the integration of AEs in planning, DSO needs a 
generic framework, that could be used to characterize the cost of any AE using the set of the same criteria.

\section{Value of flexibility}

VoF represents the highest price DSO is ready to pay to the FS providers for their aid in solving a specific issue in a distribution grid. Since VoF depends on the forecasting of the power demand, in the current paper a probabilistic approach is applied to evaluate its value under different demand forecasting scenarios in the long-term planning. The percentile $P \%$ will produce the value, which is higher than or equal to the values in the sample with $P \%$ probability [67]. By choosing the 95th percentile, the values for the worst case could be evaluated (highest cost, largest power demand, etc.).

VoF can be determined as the minimum cost of the DSO's conventional planning alternatives. In case of potential congestion in the distribution network, DSO can either reinforce the grid or curtail the loads. In the latter case, DSO will have to pay the penalty for the energy not supplied (ENS), but it will also get the benefits from the saved investments in the reinforcement (e.g. interest in the bank). VoF can be calculated as follows:

$$
V o F_{y, P \%}=\min \left\{\begin{array}{l}
C_{c o n v, T O T E X, y, P \%}, \\
C_{E N S} * E_{E N S, y, P \%}-B F_{y, P \%},
\end{array}\right.
$$

Since the reinforcement of components will allow the planners to solve the problem in the long-term perspective (assuming the forecast and planning solution are adequate), to correctly compare flexibility and conventional 
planning, the annuity is used to calculate the cost of the conventional solution as will be shown in Eq. 8. The annual cost of the conventional solution depends on the LT of the components that have to be installed. Depending on their expected LT (e.g. LT of some cables could be 40 years), the cost of reinforced components per year in most of the situations would be lower than the cost of ENS. VoF for the next year will depend on the decisions made in the previous years. By reinforcing the grid, both the cost of ENS and the cost of conventional solution in the next year will be lower, thus reducing the VoF for that year.

The benefits from postponing the reinforcements by doing load curtailment $B F_{y, P \%}$ in Eq. 1 are estimated using the cost of conventional solution without annuities (i.e. total cost). This is done in order to evaluate the amounts of income that could be generated, if the whole amount of $C_{c o n v, T O T E X, y, P \%}^{\prime}$ would be placed in the bank with certain interest rate:

$$
B F_{y, P \%}=C_{\text {conv }, T O T E X, y, P \%}^{\prime} * d r
$$

As could be seen from Eq. 1, TOTEX $C_{\text {conv,TOTEX }}$ of the conventional planning solution and the amounts of $E_{E N S}$ are required to calculate VoF. By comparing VoF with the cost of flexibility planning $C_{\text {flex }, T O T E X}$, the most cost-efficient solution is the one providing the highest benefits according to Eq. 3:

$$
B F_{f l e x, y, P \%}=V o F_{y, P \%}-C_{f l e x, T O T E X, y, P \%}
$$

Benefits in Eq. 3 could take positive or negative values. Positive ben- 


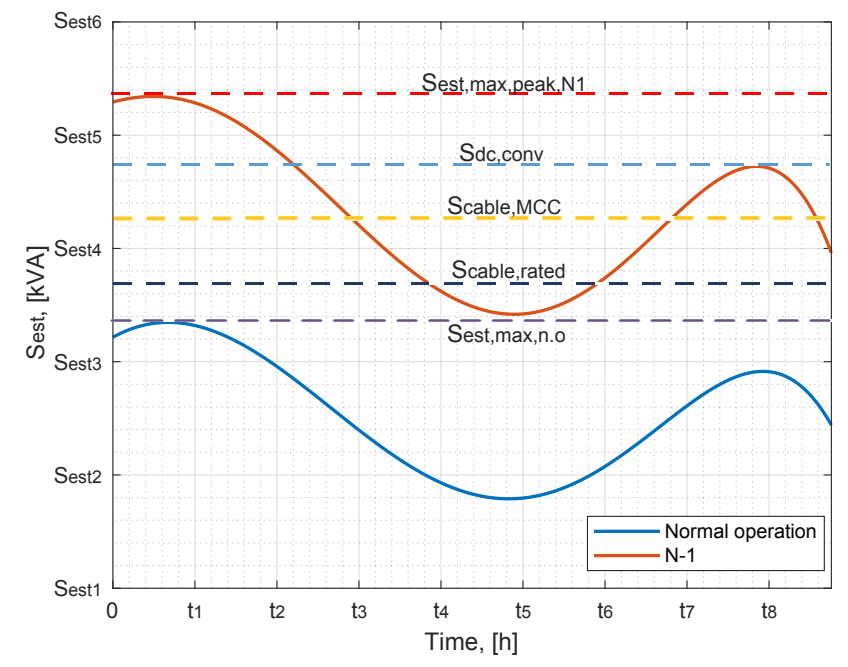

Figure 1: Estimated worst case power demand on the feeder at year $y$ for scenario $S C$ conventional planning to solve power congestion on a feeder

efits mean potential savings for the DSO from using FSs in the flexibility planning, while negative values show that the conventional solution is more cost-efficient.

Both conventional and flexibility planning types are described below.

\subsection{Conventional planning}

To illustrate how the cost of a conventional planning solution is obtained, Fig. 1 showing a potential congestion situation during N-1 is considered. Based on the forecasts made for each year until the end of the planning horizon $p l$, in some of the scenarios $S C$ power flow on one of the feeders in the distribution system is expected to exceed cable's MCC $S_{\text {cable }, M C C}$ during $\mathrm{N}-1$ contingency with estimated peak demand: 


$$
S_{\text {est }, \text { max }, \text { peak }, N 1, S C}=\max _{1 \leq y \leq p l} S_{\text {est }, \text { max }, N 1, y, S C},
$$

The conventional solution, in this case, will be to reinforce that feeder with a cable with higher MCC according to the dimensioning criteria $S_{d c, c o n v}$, which is determined using the following expression:

$$
S_{d c, \text { conv }} \geq \frac{1}{L} * S_{\text {est }, \text { max }, \text { peak }, N 1, P \%},
$$

Parameter $L$ links component's rated power and its MCC. Short-term overloading coefficient is either obtained from the component's specification or determined by the DSO based on its own experience. Different values of $L$ could be used for different durations of the overload, the shorter it is, the higher the value of $L$. For the long-term planning purposes, $L$ corresponds to the duration of the longest possible overloading event (i.e. in the range of hours).

TOTEX of any planning solution for a given year consists of two parts CAPEX and OPEX according to the following equation:

$$
C_{T O T E X, y, P \%}=C_{C A P E X, y, P \%}+C_{O P E X, y, P \%},
$$

$C_{C A P E X, y, P \%}$ and $C_{O P E X, y, P \%}$ are calculated using $C_{C A P E X, y, S C}$ and $C_{O P E X, y, S C}$ for all planning scenarios and value of percentile $P \%$.

If CAPEX and OPEX occurring at different years have to be summed together, the net present value (NPV) formula should be used. NPV allows to refer all the expenses to a current year: 


$$
C_{S C}=\sum_{y=0}^{p l} \frac{C_{y, S C}}{(1+d r)^{y}},
$$

The annuity payments from the fixed costs of the equipment, that are dependent on the LT of components, are used to calculate $C_{c o n v, C A P E X, y, S C}$ in Eq. 8:

$$
\begin{aligned}
& C_{\text {conv }, C A P E X, y, S C}=f\left(S_{d c, c o n v}\right)=
\end{aligned}
$$

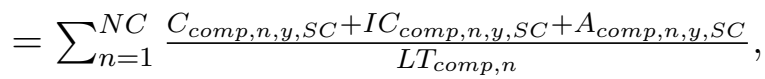

Additional expenses $A_{c o m p, n, y, S C}$ from the installation of the $n$th component could include expanding the substation in case of a new transformer, new ICT network, etc.

To get the cost of conventional solution without annuities $C_{\text {conv,TOTEX,y,SC }}^{\prime}$ for Eq. 2, the term $L T_{c o m p, n}$ in Eq. 8 should be omitted.

OPEX are expenses that depend on the number of hours components are in operation and are distributed throughout the components' LT. OPEX will vary for each scenario. Future OPEX for the year $y$ for scenario $S C$ :

$$
\begin{gathered}
C_{\text {conv }, O P E X, y, S C}=f\left(S_{e s t, y, S C}, h_{c o m p, n, y, S C}\right)= \\
=\sum_{n=1}^{N C} C_{c o m p, M \& L, n, y, S C},
\end{gathered}
$$

As was shown in Eq. 1, DSO could choose to curtail the loads and accept the penalty for $E_{E N S, y, P \%}$. In this paper $E_{E N S, y, P \%}$ is defined as the area between the $S_{c a b l e, M C C}$ and $S_{e s t, m a x, p e a k, N 1, P \%}$, i.e. between the current network capacity and forecasted maximum power demand (Fig. 1). $E_{E N S, y, P \%}$ is equal to the $E_{f l e x, y, P \%}$, that is described in the next section. 


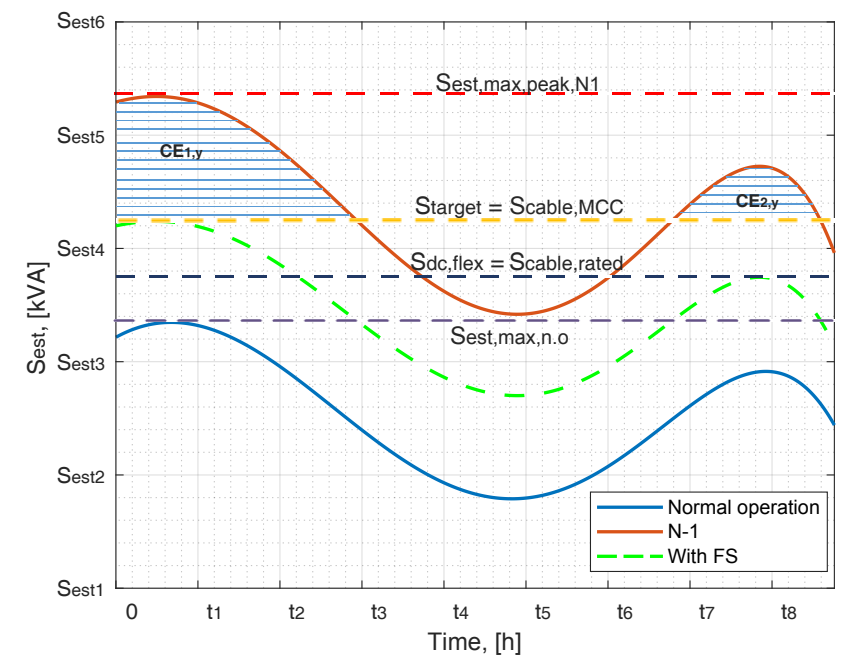

Figure 2: Estimated worst case power demand on the feeder at year $y$ for scenario $S C$ flexibility planning to solve power congestion on a feeder. CE - congestion event

\subsection{Flexibility planning}

An alternative to the conventional approach is flexibility planning. It utilizes the potential of FSs from AEs to achieve peak reduction during the congestion hours as shown in Fig. 2. The dimensioning criteria for the flexibility planning will be $S_{d c, f l e x}$ :

$$
S_{d c, f l e x} \geq \frac{1}{L} * S_{\text {target }},
$$

The power demand exceeding $S_{\text {target }}$ should be covered by the FSs. Eq. 10 is given for the case, when only one AE is used to provide all the flexibility needed. In the situations when multiple AEs are used, additional subindex $k$ denoting the $k$ th $\mathrm{AE}$ should be used together with updated power demand curves $S_{e s t, k, y, S C}$ that takes into account the effect of each $\mathrm{AE}$ and different values of $S_{\text {target }}$ for each $k$, so that: 


\begin{tabular}{|c|c|c|c|c|c|c|c|c|c|}
\hline \multicolumn{3}{|c|}{ General parameters } & \multicolumn{2}{|c|}{ CAPEX parameters } & \multicolumn{4}{|c|}{ OPEX parameters } & \multirow{2}{*}{$\begin{array}{c}\text { Evaluation } \\
\text { criteria } \\
\text { TOTEX of } A E\end{array}$} \\
\hline $\begin{array}{c}\text { What } \\
\text { service? }\end{array}$ & $\begin{array}{c}\text { Who owns } \\
\text { AE? }\end{array}$ & $\begin{array}{c}\text { How } \\
\text { credible? }\end{array}$ & $\begin{array}{l}\text { AE has to } \\
\text { be build? }\end{array}$ & $\begin{array}{l}\text { Additional } \\
\text { equipment } \\
\text { required? }\end{array}$ & $\begin{array}{l}\text { How much } \\
\text { and how } \\
\text { long? }\end{array}$ & $\begin{array}{l}\text { How } \\
\text { often? }\end{array}$ & How fast? & $\begin{array}{c}\text { How long in } \\
\text { advance? }\end{array}$ & \\
\hline G1 & G2 & G3 & $\mathrm{C} 1$ & $\mathrm{C} 2$ & $\mathrm{O} 1$ & $\mathrm{O} 2$ & $\mathrm{O3}$ & O4 & $E$ \\
\hline
\end{tabular}

Figure 3: Flexibility characterization framework

$$
S_{\text {target }}=\min _{1 \leq k \leq K_{S C}} S_{\text {target }, k, S C}
$$

If $S_{\text {target }}$ is chosen to be equal to $S_{c a b l e, M C C}, S_{d c, \text { flex }}$ will be equal to $S_{\text {cable,rated }}$ and cable reinforcement could be postponed.

In the flexibility planning, the periods when CEs are supposed to occur (shaded areas on Fig. 2) at each year $y$ of the planning horizon should be analysed and the following parameters determined for each scenario $S C$ : duration of using flexibility during each CE $D_{f l e x, i, y, S C}$, capacity $S_{f l e x, i, y, S C}$ and energy $E_{f l e x, i, y, S C}$ requested from the flexibility for each CE $i$ and total number of times flexibility should be used $N O_{f l e x, y, S C}$ during year $y$. These parameters are used for determining the $\mathrm{VoF}$ and the costs of using AEs.

The calculation of $C_{f l e x, C A P E X, y, S C}$ and $C_{f l e x, O P E X, y, S C}$ parts of the flexibility solution is described in the next section.

\section{Flexibility characterization framework}

Proposed flexibility characterization framework is shown in Fig. 3. It is made in the form of a table, where each AE capable of providing FS to the DSO is assessed with the help of different questions identifying its general, CAPEX and OPEX parameters. 


\subsection{General parameters}

These questions are used as a pre-qualification stage to select only suitable AEs:

\subsubsection{What service? (G1)}

G1 identifies what potential distribution grid issue could be solved using FSs provided by a specific AE. If FSs from an AE can be used to solve considered issue, parameter $G 1=1$, otherwise $G 1=0$;

\subsubsection{Who owns AE? (G2)}

G2 determines AE's ownership - AE can be owned either by a DSO (electrical utility) or a third party (independent - another utility, aggregator, etc.). AE's ownership will determine how much information about $\mathrm{AE}$ is available in general, its CAPEX and OPEX and DSO's confidence in AE's

performance. The ownership also influences the notice period for requesting FSs and control options (e.g. direct, indirect, etc.). Parameter G2=1 if AE is owned by the utility and 0 if AE belongs to a third party;

\subsubsection{How credible? (G3)}

G3 estimates the credibility of an AE - how confident the DSO about receiving $\mathrm{FSs}$ from $\mathrm{AE}$ upon an activation request. If $\mathrm{AE}$ can be used for providing FSs parameter $G 3=1$, if not $-G 3=0$.

The credibility of each AE should be estimated by the DSO based on the following considerations:

1. Historical records - previous records of requesting and receiving FSs from an AE, if available. Information like number of requested/answered 
activation requests and the ratio between the amounts of requested and fulfilled requests;

2. AE's ownership - described above in G2;

3. State of AE - indicates the wear and tear of an AE providing FSs;

4. The penalty for not fulfilling activation request - will determine how important the activation request is for the FSs provider.

\subsection{CAPEX parameters}

"CAPEX parameters" are used to determine the potential CAPEX part of the $C_{f l e x, T O T E X, y, P \%}$ :

\subsubsection{AE has to be built? (C1)}

$C 1$ identifies whether an $\mathrm{AE}$ has to be built prior to the provision of FSs, parameter $C 1=1$ if construction is required and 0 otherwise. Based on the answer to the question $G 2$ about AE's ownership, this cost may be included in the CAPEX;

\subsubsection{Additional equipment required? (C2)}

Additional equipment such as ICT infrastructure for DR or transformer substation expansion to fit the transformer with an OLTC could be required to enable the provision of the FSs from a specific AE. Parameter $C 2=1$ if there is a need for additional equipment and 0 otherwise.

\subsection{OPEX parameters}

OPEX part of the total cost of the flexibility planning $C_{f l e x, T O T E X, y, P \%}$ is determined through "OPEX parameters". It is proposed to estimate OPEX via cost functions corresponding to the questions below. The cost from each 
cost function is determined for each planning scenario, the final value is then chosen using the $P \%$ percentile.

\subsubsection{How much and how long? (O1)}

The cost of the requested energy from FS for $i$ th CE can be described by a cost function $F_{O 1}\left(S_{f l e x, k, i, y, m e a n, S C}, D_{f l e x, k, i, y, S C}\right)$;

\subsubsection{How often? (O2)}

$F_{O 2}\left(N O_{f l e x, k, y, S C}\right)$ is a cost function showing the cost of total number of times FS is used;

\subsubsection{How fast? (O3)}

Cost function $F_{O 3}\left(R O C_{f l e x, k, i, y, S C}\right)$ determines the cost of AE's ramping up/down capabilities in providing FSs;

\subsubsection{How long in advance? (O4)}

$O 4$ determines how much in advance warning has to be given to the $\mathrm{AE}$ for providing FS: $F_{O 4}\left(N P_{f l e x, k, i, y, S C}\right)$.

\subsection{Evaluation criteria}

Total cost of a flexibility planning solution with one or several AEs

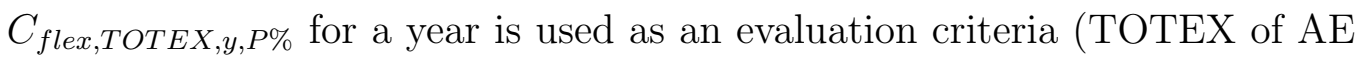
(E)) in the proposed framework. It consists of the CAPEX and OPEX parts, that are described below.

Based on the proposed flexibility characterization framework, CAPEX of the flexibility solution $C_{f l e x, C A P E X, y, S C}$ can be calculated as follows: 


$$
\begin{gathered}
C_{f l e x, C A P E X, y, S C}=\sum_{\substack{k=1, G 1_{k}, G 3_{k} \neq 0}}^{K_{S C}} C_{f l e x, C A P E X, k, y, S C}= \\
\sum_{\substack{k=1, G 1_{k}, G 3_{k} \neq 0}}^{K_{S C}}\left(G 2_{k} * C 1_{k} * C_{A E, k, y, S C}+C 2_{k} * A_{A E, k, y, S C}\right),
\end{gathered}
$$

$C_{f l e x, C A P E X, y, P \%}$ is calculated using $C_{f l e x, C A P E X, y, S C}$ for all planning scenarios and the $P \%$ percentile (Eq. 6-7). The cost $C_{A E, k, y, S C}$ is a function of the chosen $S_{\text {target }}$.

OPEX from all used AEs $C_{f l e x, O P E X, y, S C}$ at the year $y$ in scenario $S C$ depends on the following cost functions and parameters:

$$
\begin{aligned}
& C_{f l e x, O P E X, y, S C}=\sum_{k=1}^{K_{S C}} C_{f l e x, O P E X, k, y, S C}= \\
& =\sum_{k=1}^{K_{S C}} f\left(G 1_{k}, G 2_{k}, G 3_{k}, C\left(F_{O 1_{k, y}}\right)_{S C},\right. \\
& \left.C\left(F_{O 2_{k, y}}\right)_{S C}, C\left(F_{O 3_{k, y}}\right)_{S C}, C\left(F_{O 4_{k, y}}\right)_{S C}\right),
\end{aligned}
$$

In the current paper, the following expression is used to represent the relationship between all the parameters and cost functions for OPEX calculation: 
Table 1: Costs included in the CAPEX and OPEX of different AE/FSs according to the flexibility characterization framework

\begin{tabular}{|c|c|c|c|c|c|c|}
\hline \multirow{2}{*}{$\mathrm{AE} / \mathrm{FS}$} & \multirow{2}{*}{$\mathrm{AE}$} & \multicolumn{2}{|c|}{ Costs included in CAPEX } & \multicolumn{2}{|c|}{ Costs included in OPEX } & \multirow{2}{*}{ Cost functions } \\
\hline & & Main & Additional & Main & Additional & \\
\hline DR & $\begin{array}{l}\text { Consumer's } \\
\text { equipment }\end{array}$ & - & $\begin{array}{l}\text { ICT and control } \\
\text { infrastructure }\end{array}$ & Supplied energy & Energy difference & O1-O4 \\
\hline BESS & BESS & - & $\begin{array}{l}\text { ICT and control } \\
\text { infrastructure }\end{array}$ & Supplied energy & $\begin{array}{c}\text { Recharge cycles, } \\
\text { recovery cost } \\
\text { of BESS unit }\end{array}$ & O1-O2 \\
\hline RE & $\mathrm{CB}$ & CBs & Tie-lines (TLs) & Number of SWs & - & $\mathrm{O} 2$ \\
\hline DLR & Cable & - & $\begin{array}{c}\text { Soil temperature } \\
\text { sensors }\end{array}$ & Reduction in LT & - & $\mathrm{O} 1$ \\
\hline
\end{tabular}

$$
\begin{aligned}
& C_{f l e x, O P E X, y, S C}=\sum_{\substack{k=1, G 1_{k}, G 3_{k} \neq 0}}^{K_{S C}} C_{f l e x, O P E X, k, y, S C}= \\
& =\sum_{\substack{k=1, G 1_{k}, G 3_{k} \neq 0}}^{K_{S C}}\left[C\left(F_{O 1_{k, y}}\right)_{S C}+C\left(F_{O 2_{k, y}}\right)_{S C}+\right. \\
& +C\left(F_{O 3_{k, y}}\right)_{S C}+C\left(F_{O 4_{k, y}}\right)_{S C}+C_{A E, f e a t, k, y, S C}+ \\
& \left.+G 2_{k} * C_{A E, M \& L, k, y, S C}\right]
\end{aligned}
$$

Similar to the CAPEX part, $C_{f l e x, O P E X, y, P \%}$ is calculated using $C_{f l e x, O P E X, y, S C}$ and Eq. 6-7.

Table 1 shows what costs are included in CAPEX and OPEX for each of the four considered AEs/FSs. CAPEX costs are related to the installations of the main and additional components, where the main component is an AE itself. OPEX would typically include the cost of the supplied energy or the cost of the extra degradation caused by using a particular AE/FS. The 
detailed explanation of how the cost of one of the FS - DLR is modelled is given in the Appendix as an example.

For BESS, RE and DLR the costs could be to a certain degree linked to the physical processes occurring in the devices, while the cost of the DR is more subjective. An extra cost that should be added to the DR is the difference in the energy cost at original time (when the customer intends to use equipment) and later time (when equipment is actually used due to postponement). This would ensure, that the DR owner will not have to pay higher energy costs for postponing its power consumption. An extra cost for the BESS includes a cost of a number of recharging cycles used to provide requested energy (since each cycle will cause BESS degradation) and the partial cost recovery of a BESS unit cost.

\section{Case study}

\subsection{System topology}

The system considered in a case study is shown in Fig. 4. It is a part of the real $10 \mathrm{kV}$ distribution network of Nordhavn area in Copenhagen, Denmark. The system is supplied from the $30 / 10 \mathrm{kV}$ main substation (MS) through the four main cables MS-1, MS-10, MS-2, and MS-20. The topology is organized in two loops with the possibility to shift the electrical load from one feeder to the other in case of a failure or a fault (internal RE via TL T19-T110 or T27-T28).

Each bus represents a $10 \mathrm{kV}$ side of the secondary substation with one or several distribution transformers. The loads are connected to the $0.4 \mathrm{kV}$ side of the transformers (Fig. 5). The power demand at each substation 


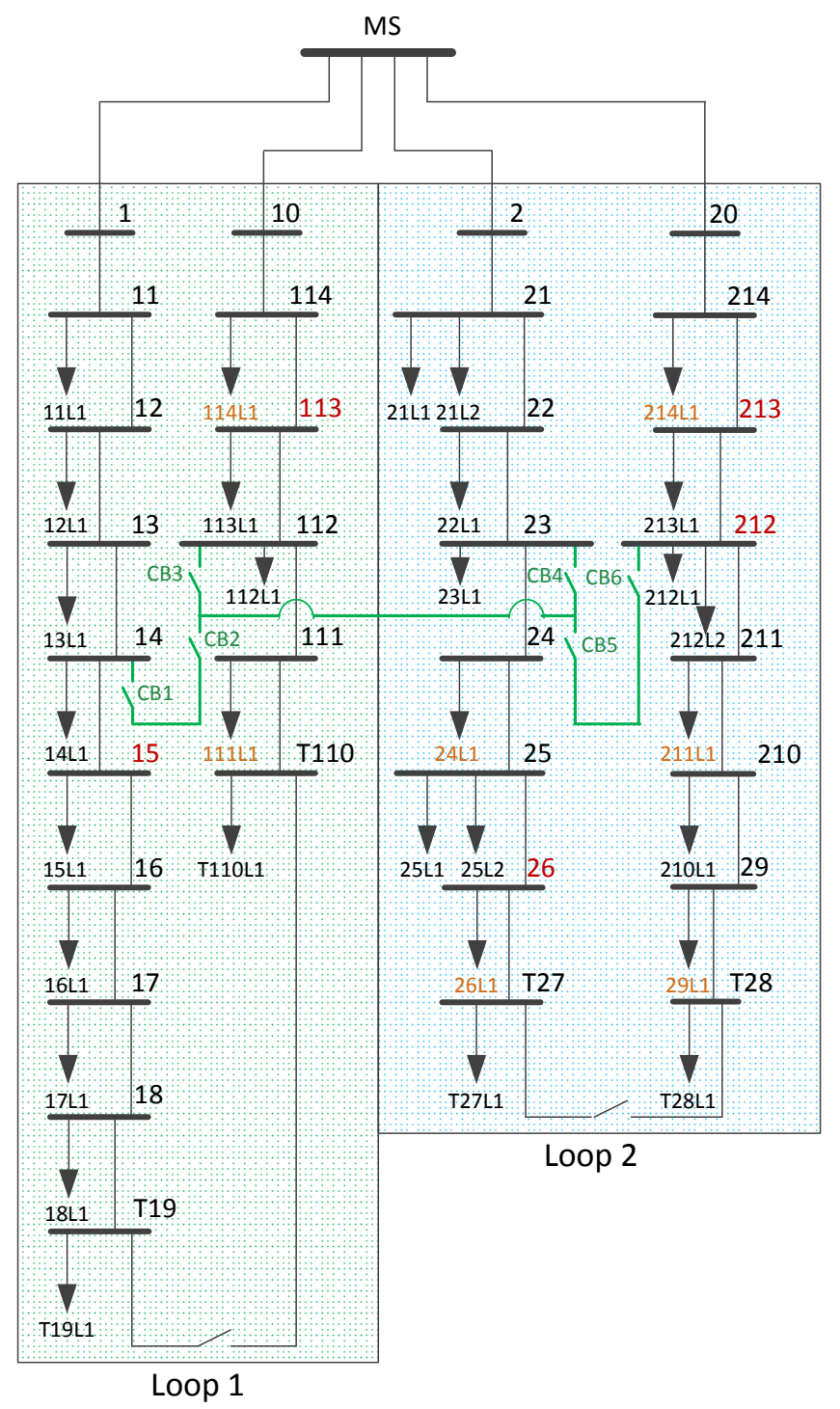

Figure 4: Part of the $10 \mathrm{kV}$ distribution system of Nordhavn area used in the case study, nodes with loads are 0.4 kV. Figure explanations: MS - main substation; L - load node; T - node with TL; CB - circuit-breaker; nodes with the red font have BESS; nodes with the orange font have DR; new supply paths to enable RE with an external loop are highlighted in green 


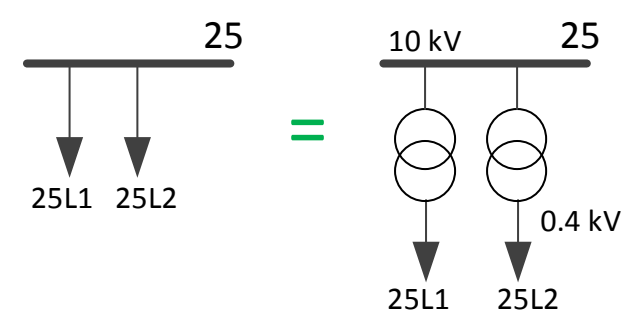

Figure 5: Representation of the loads depicted in Fig. 4

is formed by a combination of various residential, commercial and light industrial consumers. The time-series consumption data with 1-h resolution is synthesized using the annual energy measurements from actual Nordhavn consumers for the year 2016 and corresponding demand curves for each load category. Maximum power of the substations is given in Table AI in the Appendix.

\subsection{Flexibility sources}

The system has a number of FSs providers. DR and BESS utilize the consumers' equipment present in the grid to provide FSs. RE and DLR use the distribution network components as the source of FSs.

Loads at the $0.4 \mathrm{kV}$ nodes 111L1, 114L1, 24L1, 26L1, 29L1, 211L1 and 214L1 can provide DR. In the current paper the capacity of DR is considered as a percentage of the total substation load and change from year to year with the upper limit of $10 \%$ of the total load.

BESS units of various capacity and energy are connected through their own designated transformers to the $10 \mathrm{kV}$ nodes of 15, 113, 26, 212 and 213. Parameters of BESS are given in Table AII in Appendix.

Flexibility could be obtained by shifting part of the electrical loads to the 
feeders in another loop (external RE). To enable external RE three TLs and six CBs have to be constructed (shown in green in Fig. 4).

By installing sensors to measure soil temperature and making a thermal model of the cable it is possible to apply DLR at any cable. The extra capacity given by the DLR is changing from year to year depending on the temperature and the number of rainfall with the upper limit of $15 \%$ for the cables in clay.

In order to facilitate the integration of the FSs providers in the longterm planning, without compromising DSO's performance in a benchmarking $[68,69]$ and its ability to supply customers with power, it is assumed that the FSs from AEs are provided based on the long-term contracts. Those contracts specify the maximum amount of provided capacity, the maximum duration of FSs and limit the number of times, services are provided during a specified time interval (e.g. a year). It is assumed that there is no market, where the DSO can contract the FSs from.

\section{Results}

Time-series load profiles for the year 2016 are used as a base for creating forecasts for the period of 4 years with an yearly interval. Each load is decomposed into a base trend, seasonal variation and stochastic component. At each year ten different scenarios of how the base trend and the seasonal variations will change are considered, resulting in a total of 100 forecasts. Example of the different scenarios of power demand evolution is given in Fig. A1 in Appendix.

The analysis of the forecasted scenarios shows that cables C2-21, C214- 
Table 2: Detected CEs in cables. Values for power, energy, number of CEs and duration are obtained by using 95 th percentile

\begin{tabular}{|c|c|c|c|c|c|c|c|c|c|c|c|}
\hline \multicolumn{6}{|c|}{ Year 3} & \multicolumn{6}{|c|}{ Year 4} \\
\hline Cable & $\begin{array}{c}\mathrm{SC} \\
\text { with } \\
\mathrm{CE},[-]\end{array}$ & $\begin{array}{c}S_{f l e x, 3,95}, \\
{[\mathbf{k V A}]}\end{array}$ & $\begin{array}{l}E_{\text {flex }, 3,95}, \\
{[\mathbf{k V A h}]}\end{array}$ & $\begin{array}{c}N O_{f l e x, 3,95}, \\
{[-]}\end{array}$ & $\begin{array}{c}D_{\text {flex }, 3,95} \\
{[\mathbf{h}]}\end{array}$ & Cable & $\begin{array}{c}\mathrm{SC} \\
\text { with } \\
\mathrm{CE},[-]\end{array}$ & $\begin{array}{c}S_{\text {flex }, 4,95}, \\
{[\mathrm{kVA}]}\end{array}$ & $\begin{array}{l}E_{f l e x, 4,95}, \\
{[\mathbf{k V A h}]}\end{array}$ & $\begin{array}{c}N O_{f l e x, 4,95}, \\
{[-]}\end{array}$ & $\begin{array}{c}D_{f l e x, 4,95}, \\
{[\mathbf{h}]}\end{array}$ \\
\hline $\mathrm{C} 2-21$ & 99 & 1334.4 & 3578.5 & 8 & 2 & C2-21 & 99 & 1538.3 & 4867.9 & 11 & 2 \\
\hline C214-213 & 93 & 975.8 & 1543.9 & 4 & 2 & C213-212 & 16 & 166.7 & 166.7 & 1 & 1 \\
\hline \multirow[t]{2}{*}{ C20-214 } & \multirow[t]{2}{*}{99} & \multirow[t]{2}{*}{1334.4} & \multirow[t]{2}{*}{3578.5} & \multirow[t]{2}{*}{8} & \multirow[t]{2}{*}{8} & C214-213 & 95 & 1158.1 & 2359.3 & 5 & 2 \\
\hline & & & & & & C20-214 & 99 & 1538.3 & 4867.9 & 11 & 2 \\
\hline
\end{tabular}

Table 3: Cost of changing the cables in the conventional planning

\begin{tabular}{c|c|c|c|c|c} 
Cable & $\begin{array}{c}\text { Length, } \\
{[\mathrm{km}]}\end{array}$ & $\begin{array}{c}\text { Old } \\
\text { cable }\end{array}$ & $\begin{array}{c}\text { New } \\
\text { cable }\end{array}$ & $\begin{array}{c}\text { Cost, } \\
{[\mathrm{k} €]}\end{array}$ & $\begin{array}{c}\text { Year } \\
\text { to } \\
\text { invest }\end{array}$ \\
\hline $\mathbf{C 2 - 2 1}$ & 1.15 & $3 \times 240$ & $3 \times 300$ & 152.9 & 2 \\
\hline $\mathbf{C 2 1 3 - 2 1 2}$ & 0.17 & $3 \times 240$ & $3 \times 300$ & 22.3 & 3 \\
\hline $\mathbf{C 2 1 4 - 2 1 3}$ & 0.12 & $3 \times 240$ & $3 \times 300$ & 15.6 & 2 \\
\hline $\mathbf{C 2 0 - 2 1 4}$ & 1.77 & $3 \times 240$ & $3 \times 300$ & 236.5 & 2
\end{tabular}

213 and C20-214 could experience overload in year 3. Cable C213-212 could also be overloaded in year 4 in addition to the previous three. The overload could potentially occur during the worst case of N-1 contingency (fault at one of the main cables in a loop, when the remaining main cable takes the whole load of the loop). The information about detected CEs is summarized in Table 2. 
Table 4: Cost of the conventional planning solution

\begin{tabular}{c|c|c} 
& Year 3 & Year 4 \\
\hline$C_{\text {conv }, C A P E X, y, 95},[\mathrm{k} €]$ & 10.1 & 0.6 \\
\hline$C_{\text {conv }, O P E X, y, 95},[\mathrm{k} €]$ & 4.6 & 0.2 \\
\hline$C_{\text {conv }, T O T E X, y, 95},[\mathrm{k} €]$ & 14.7 & 0.8 \\
\hline$V_{O O F}, 95,[\mathrm{k} €]$ & 14.7 & $0.8 / 15.5$
\end{tabular}

\subsection{Conventional planning}

As was previously mentioned, the conventional solution for handling CEs is to invest in the reinforcement of the cables. The costs of changing the cables in the conventional planning and CAPEX, OPEX, TOTEX and VoF are given in the Tables $3-4$, respectively.

The entire process of changing the cables is assumed to take one year, therefore the investment decision should be taken one year before the CEs could occur. The cost of the cables in Table 3 include the cost of components and their installation.

The costs $C_{\text {conv }, C A P E X, y, 95}, C_{\text {conv }, O P E X, y, 95}$ and $C_{\text {conv,TOTEX,y,95 shown in }}$ Table 4 are the reinforcement costs for the cables. Three cables: C2-21, C214-213 and C20-214 should be reinforced in year 3 and one cable C213212 - in year 4. VoF for the year 3 is calculated using Eq. 1 assuming all three cables would be reinforced in the conventional planning solution. As was mentioned earlier, VoF in year 4 will depend on the decisions made in year 3. Therefore, two values for the VoF are given for year 4. The first value assumes that the DSO decides to reinforce the cables in year 3 (cables C2-21, C214-213 and C20-214). In that case, the cost of the conventional solution 
Table 5: Parameters used in the cost functions

\begin{tabular}{r|c} 
Parameter & Value \\
\hline Cost of ENS, [€/kVAh] & 40 \\
Cost of losses, [€/kWh] & 0.1 \\
Discount or interest rate, [-] & 0.05 \\
Base cost of energy provided by DR, [€/kWh] & 0.1 \\
Cost of ICT for DR, BESS, [k€/unit] & 0.5 \\
Base cost of energy provided by BESS, [€/kWh] & 0.5 \\
Cost of CB, [k€] & 8 \\
Max. number of SWs, [-] & 50000 \\
Cost of sensors for DLR, [k€/km] & 1.0 \\
Cable LT, [year] & 40
\end{tabular}

used in Eq. 1 for year 4 is just the cost of the reinforcement of cable C213-212. The second value of VoF is calculated for the case, when the DSO decides to postpone the reinforcement of cables in year 3. The cost of conventional planning solution now is the sum of reinforcement costs of cables in year 3 and 4. As could be seen from Table 4, the longer reinforcement is deferred the higher is the VoF.

\subsection{Flexibility planning}

Since the probability that the worst case of N-1 will coincide with the high power demand is not high, it may be more economically beneficial to rely on the flexibility options that require much lower CAPEX investments. The flexibility planning is used to identify which AEs could potentially help in handling detected CEs. The calculation of the total cost of AE is done as 
described in the flexibility characterization framework using cost functions as the one for RE in Fig. 6. Other cost functions for DR, BESS and DLR could be found in Appendix (Fig. A2 - A8) with parameters used to define them given in Table 5 .

The maximum capacity and energy that could be provided by each $\mathrm{AE}$ and the costs of utilizing that $\mathrm{AE}$ are summarized in Table 6. $S_{f l e x, y, P \%}$ and $E_{f l e x, y, P \%}$ are used to obtain the costs of using AEs. Due to the network's topology, to avoid any potential CE, an AE should be able to provide $S_{f l e x, y, P \%}$ and $E_{f l e x, y, P \%}$ equal to the ones for the main cables C2-21 or C20-214. If the total amount of FSs from any particular type of AEs is not sufficient to cover either $S_{f l e x, y, P \%}$ or $E_{f l e x, y, P \%}$ shown in Table 2, the maximum capacity and energy that this AE could supply are used for the calculations. The costs are calculated in the assumption that only one type of AE is used in both year 3 and 4 . The costs of using AEs in year 4 will depend on whether the DSO decided to utilize their FSs in year 3. If the DSO decided to use AEs in year 3, most of the CAPEX costs would be covered that year. That makes the CAPEX costs in year 4 much smaller as there are fewer new AEs that should be enabled by the DSO. This allows having zero CAPEX for RE in year 4, after it was constructed in year 3 .

With the exception of RE in year 3, no AE/FS can provide the required capacity and energy alone. Therefore a combination of multiple AEs should be used. The final solution, which uses the combination of DLR and BESS is given in Table 7. Comparison of the TOTEX for both years shown in Table 7 with the VoF in Table 4 reveals the amount of potential benefits $B F_{\text {flex }}$ for the DSO that could be achieved. Utilizing FSs from DLR and BESS in 


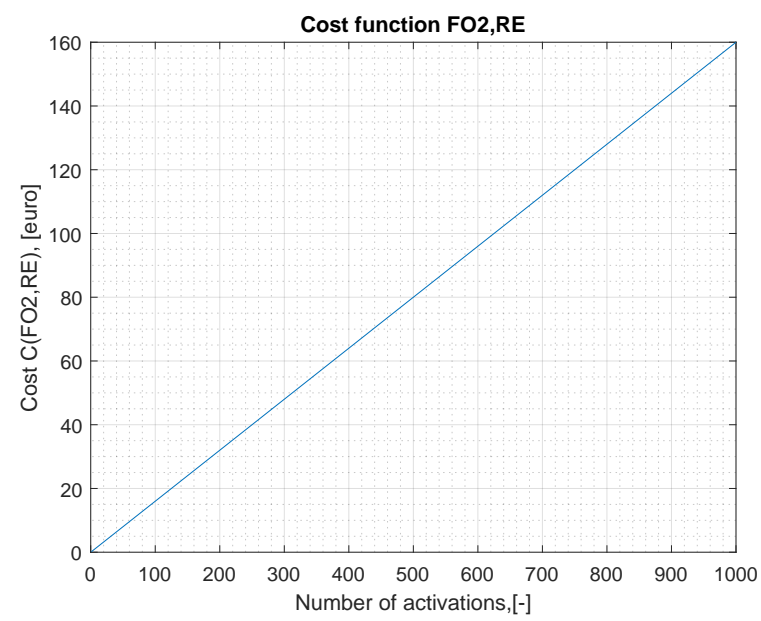

Figure 6: Cost function FO2 for RE in years 3 and 4

year 3 will allow the DSO to save $10.5 \mathrm{k} €$, which is equal to savings of ca $71.5 \%$ of the expenses that the DSO would incur during this year according to conventional planning. Two scenarios are possible in year 4: if the DSO invested in the reinforcements in year 3 , the $\mathrm{VoF}$ in year 4 is only $0.8 \mathrm{k} €$ and therefore using AEs will bring the benefits of $0.5 \mathrm{k} €$ (saving $62.5 \%$ of the expenses in conventional planning); if the DSO did not upgrade its network in year 3, the VoF will become higher and therefore the benefits will reach $15.2 \mathrm{k} €$ (saving 98.0\% of the expenses in case of reinforcement). As could be seen, involving the FSs from AEs in the distribution network planning can make the network more cost-efficient, while keeping its performance on an acceptable level.

\section{Conclusions and future work}

The paper proposes the flexibility characterization framework. The aim of the framework is to generalize the process of cost estimation of various 
Table 6: Maximum capacity and energy, and costs of each AE/FS available in the distribution network

\begin{tabular}{c|c|c|c|c|c} 
& Parameter & DR & BESS & RE & DLR \\
\hline \multirow{4}{*}{ Year 3 } & $S_{\text {flex }, 3,95,[\mathrm{kVA}]}$ & 227.5 & 808.0 & 1334.4 & 1284.2 \\
\cline { 2 - 6 } & $E_{\text {flex }, 3,95,[\mathrm{kVAh}]}$ & 835.3 & 3288.4 & 3578.5 & 3538.5 \\
\cline { 2 - 6 } & $C_{\text {flex }, \text { CAPEX }, 3,95,[\mathrm{k} €]}$ & 2.3 & 1.6 & 194.3 & 3.0 \\
\cline { 2 - 6 } & $C_{\text {flex }, O P E X, 3,95},[\mathrm{k} €]$ & 1.0 & 1.5 & 0.002 & 0.008 \\
\cline { 2 - 6 } & $C_{\text {flex }, T O T E X, 3,95},[\mathrm{k} €]$ & 3.3 & 3.1 & 194.3 & 3.0 \\
\hline \multirow{4}{*}{ Year 4 } & $S_{\text {flex }, 4,95,[\mathrm{kVA}]}$ & 214.7 & 808.0 & 1538.3 & 1390.6 \\
\cline { 2 - 6 } & $E_{\text {flex }, 4,95,[\mathrm{kVAh}]}$ & 1173.7 & 4367.8 & 4867.9 & 4742.0 \\
\cline { 2 - 6 } & $C_{\text {flex }, \text { CAPEX }, 4,95,[\mathrm{k} €]}$ & 0.9 & 0.9 & 0 & 0.2 \\
\cline { 2 - 6 } & $C_{\text {flex }, O P E X, 4,95},[\mathrm{k} €]$ & 1.7 & 1.4 & 0.003 & 0.01 \\
\cline { 2 - 6 } & $C_{\text {flex }, T O T E X, 4,95},[\mathrm{k} €]$ & 2.6 & 2.3 & 0.003 & 0.21 \\
\cline { 2 - 6 }
\end{tabular}

Table 7: Cost of the solution using flexibility

\begin{tabular}{c|c|c} 
& Parameter & \\
\hline \multirow{2}{*}{$\begin{array}{c}\text { Year 3 } \\
\text { (DLR \& BESS })\end{array}$} & $C_{\text {flex }, C A P E X, 3,95},[\mathrm{k} €]$ & 4.2 \\
\cline { 2 - 3 } & $C_{\text {flex }, O P E X, 3,95},[\mathrm{k} €]$ & 0.1 \\
\cline { 2 - 3 } & $C_{\text {flex }, T O T E X, 3,95},[\mathrm{k} €]$ & 4.2 \\
\cline { 2 - 3 } Year 4 & $B F_{\text {flex }, 3,95,[\mathrm{k} €]}$ & 10.5 \\
\hline \multirow{4}{*}{ (DLR \& BESS) } & $C_{\text {flex }, C A P E X, 4,95},[\mathrm{k} €]$ & 0.2 \\
\cline { 2 - 3 } & $C_{\text {flex }, O P E X, 4,95},[\mathrm{k} €]$ & 0.06 \\
\cline { 2 - 3 } & $C_{\text {flex }, T O T E X, 4,95},[\mathrm{k} €]$ & 0.3 \\
\cline { 2 - 3 } & $B F_{\text {flex }, 4,95},[\mathrm{k} €]$ & $0.5 / 15.2$ \\
&
\end{tabular}


AEs/FSs that could be used as an alternative to the traditional grid reinforcement. Comparing TOTEX from using AEs with the VoF, the DSO planners will have a useful tool to aid them in the decision making process. Provided case study demonstrates the application of the framework in the part of an actual $10 \mathrm{kV}$ distribution system of Nordhavn area in Copenhagen.

Proposed framework could be used by the DSOs to decide which AEs to choose for providing FSs in their networks. The methodology for the cost estimation of the AEs and VoF could be applied by the DSOs to design the price signals for their DR programs. Potential AEs such as electric heat boosters tested in EnergyLab Nordhavn project [70] could be integrated into distribution network planning with the use of the presented framework. By streamlining the process of integrating new flexibility that can provide load reduction as well as load increase, a larger number of renewables could be connected to the electrical network.

In regards to the future work, the identification of the parameters used in the cost functions could be improved by analyzing data from the DSOs that are already using different types of AEs in practice. In this paper, the methodology for VoF estimation is given from the perspective of the DSO. However, the VoF is different for different stakeholders involved in the network operation (e.g. aggregator). This should be further investigated. The DSO is not the only entity that might require FSs from AEs in its network. In the future, a competition for the FSs between a DSO and transmission system operator could be expected, which will influence the prices the DSO should offer to the owners of AEs. 


\section{Acknowledgment}

This work was supported by the Danish Energy Development Programme (EUDP) through the EnergyLab Nordhavn (Grant : EUDP 64015-0055).

\section{References}

[1] N. Jenkins, J. Ekanayake, G. Strbac, Distributed Generation, The Institution of Engineering and Technology, 2010.

[2] N. Strachan, H. Dowlatabadi, Distributed generation and distribution utilities, Energy Policy 30 (8) (2002) 649-661.

[3] H. Saboori, R. Hemmati, S. M. S. Ghiasi, S. Dehghan, Energy storage planning in electric power distribution networks-a state-of-the-art review, Renewable and sustainable energy reviews 79 (2017) 1108-1121.

[4] N. S. Chouhan, M. Ferdowsi, Review of energy storage systems, in: 41st North American Power Symposium, IEEE, 2009, pp. 1-5.

[5] F. Geth, J. Tant, E. Haesen, J. Driesen, R. Belmans, Integration of energy storage in distribution grids, in: IEEE PES General Meeting, IEEE, 2010, pp. 1-6.

[6] M. Akmal, B. Fox, J. D. Morrow, T. Littler, Impact of heat pump load on distribution networks, IET Generation, Transmission \& Distribution 8 (12) (2014) 2065-2073.

[7] A. M. Haidar, K. M. Muttaqi, D. Sutanto, Technical challenges for electric power industries due to grid-integrated electric vehicles in low volt- 
age distributions: A review, Energy conversion and management 86 (2014) 689-700.

[8] J. Zhao, Y. Wang, C. Wang, F. Lin, L. Y. Wang, Maximizing the penetration of plug-in electric vehicles in distribution network, in: 2013 IEEE Transportation Electrification Conference and Expo (ITEC), IEEE, 2013, pp. 1-6.

[9] N. I. Yusoff, A. A. M. Zin, A. B. Khairuddin, Congestion management in power system: A review, in: 2017 3rd International Conference on Power Generation Systems and Renewable Energy Technologies (PGSRET), IEEE, 2017, pp. 22-27.

[10] A. Haque, P. Nguyen, W. Kling, F. Bliek, Congestion management in smart distribution network, in: 2014 49th International Universities Power Engineering Conference (UPEC), IEEE, 2014, pp. 1-6.

[11] C. Zhao, C. Gu, F. Li, M. Dale, Understanding lv network voltage distribution-uk smart grid demonstration experience, in: 2015 IEEE Power \& Energy Society Innovative Smart Grid Technologies Conference (ISGT), IEEE, 2015, pp. 1-5.

[12] H. Holttinen, A. Tuohy, M. Milligan, E. Lannoye, V. Silva, S. Müller, L. Sö, et al., The flexibility workout: managing variable resources and assessing the need for power system modification, IEEE Power and Energy Magazine 11 (6) (2013) 53-62.

[13] K. Spiliotis, A. I. R. Gutierrez, R. Belmans, Demand flexibility versus 
physical network expansions in distribution grids, Applied energy 182 (2016) 613-624.

[14] S. Klyapovskiy, S. You, R. C. Domens, H. W. Bindner, H. Cai, Utilizing flexibility services from a large heat pump to postpone grid reinforcement, in: 2018 IEEE Student Conference on Electric Machines and Systems, IEEE, 2018, pp. 1-6.

[15] S. Mathieu, Q. Louveaux, D. Ernst, B. Cornélusse, Coordination of flexibility services within a distribution network.

[16] C. D'Adamo, S. Jupe, C. Abbey, Global survey on planning and operationof active distribution networks update of cigre c6.11 working groupactivities, in: 20th Int. Conf. and Exhibition on Electricity Distribution Part 1,2009. CIRED 2009, 2009, pp. 1-4.

[17] J. Liu, H. Gao, Z. Ma, Y. Li, Review and prospect of active distribution system planning, Journal of Modern Power Systems and Clean Energy 3 (4) (2015) 457.

[18] F. Pilo, G. Celli, E. Ghiani, G. G. Soma, New electricity distribution network planning approaches for integrating renewable, Wiley Interdisciplinary Reviews: Energy and Environment 2 (2) (2013) 140-157.

[19] S. A. A. Kazmi, M. K. Shahzad, A. Z. Khan, D. R. Shin, Smart distribution networks: A review of modern distribution concepts from a planning perspective, Energies 10 (4) (2017) 501. 
[20] S. Karagiannopoulos, P. Aristidou, G. Hug, Hybrid approach for planning and operating active distribution grids, IET Generation, Transmission \& Distribution 11 (3) (2017) 685-695.

[21] S. Huang, Q. Wu, Z. Liu, A. H. Nielsen, Review of congestion management methods for distribution networks with high penetration of distributed energy resources, in: IEEE PES Innovative Smart Grid Technologies, Europe, IEEE, 2014, pp. 1-6.

[22] R. Nawzad, Short-time overloading of power transformers (2011).

[23] S. Swingler, K. Barber, J. Daly, R. Awad, J. Antic, W. Zenger, Statistics of ac underground cables in power networks, CIGRE TB 338.

[24] J. Xiao, B. Su, S. Liu, F. Li, N-1 loadability for distribution systems, in: 2015 IEEE Power \& Energy Society General Meeting, IEEE, 2015, pp. $1-5$.

[25] M. Sun, P. Djapic, M. Aunedi, D. Pudjianto, G. Strbac, Benefits of smart control of hybrid heat pumps: An analysis of field trial data, Applied Energy 247 (2019) 525-536.

[26] R. Bernards, J. Reinders, E. Klaassen, J. Morren, H. Slootweg, Metaanalysis of the results of european smart grid projects to quantify residential flexibility, in: CIRED Workshop 2016, IET, 2016, pp. 1-4.

[27] M. Ginsberg, S. Goeta, V. Fthenakis, Grid flexibility and the cost of integrating variable renewable energy: Toward a renewable energy integration adder for san diego gas and electric service territory and the 
california electric grid, in: 2018 IEEE 7th World Conference on Photovoltaic Energy Conversion (WCPEC)(A Joint Conference of 45th IEEE PVSC, 28th PVSEC \& 34th EU PVSEC), IEEE, 2018, pp. 1402-1405.

[28] R. G. Junker, A. G. Azar, R. A. Lopes, K. B. Lindberg, G. Reynders, R. Relan, H. Madsen, Characterizing the energy flexibility of buildings and districts, Applied energy 225 (2018) 175-182.

[29] K. Kouzelis, I. D. de Cerio Mendaza, B. Bak-Jensen, Probabilistic quantification of potentially flexible residential demand, in: 2014 IEEE PES General Meeting - Conference \& Exposition, IEEE, 2014, pp. 1-5.

[30] H. Ji, C. Wang, P. Li, J. Zhao, G. Song, J. Wu, Quantified flexibility evaluation of soft open points to improve distributed generator penetration in active distribution networks based on difference-of-convex programming, Applied energy 218 (2018) 338-348.

[31] H. Ji, C. Wang, P. Li, G. Song, H. Yu, J. Wu, Quantified analysis method for operational flexibility of active distribution networks with high penetration of distributed generators, Applied Energy 239 (2019) 706-714.

[32] G. Oluleye, J. Allison, G. Hawker, N. Kelly, A. D. Hawkes, A two-step optimization model for quantifying the flexibility potential of power-toheat systems in dwellings, Applied energy 228 (2018) 215-228.

[33] S. Klyapovskiy, S. You, H. Cai, H. W. Bindner, Incorporate flexibility in distribution grid planning through a framework solution, International Journal of Electrical Power \& Energy Systems 111 (2019) 66-78. 
[34] M. Zvirgzdina, O. Bogdanova, J. Spiridonovs, Aggregator as cost optimization tool for energy demand.

[35] G. Gutiérrez-Alcaraz, J. Tovar-Hernández, C.-N. Lu, Effects of demand response programs on distribution system operation, International Journal of Electrical Power \& Energy Systems 74 (2016) 230-237.

[36] D. P. Chassin, J. Stoustrup, P. Agathoklis, N. Djilali, A new thermostat for real-time price demand response: Cost, comfort and energy impacts of discrete-time control without deadband, Applied Energy 155 (2015) $816-825$.

[37] M. H. Abbasi, A. Rajabi, M. Taki, L. Li, J. Zhang, S. Ghavidel, M. J. Ghadi, Risk-constrained offering strategies for a price-maker demand response aggregator, in: 2017 20th International Conference on Electrical Machines and Systems (ICEMS), IEEE, 2017, pp. 1-6.

[38] J. Domínguez, J. P. Chaves-Ávila, T. G. San Román, C. Mateo, The economic impact of demand response on distribution network planning, in: 2016 Power Systems Computation Conference (PSCC), IEEE, 2016, pp. 1-7.

[39] Q. Li, J. Hu, C. Jian, Q. Zhao, Dispatch model of active distribution network based on demand response.

[40] C. Gu, X. Yan, Z. Yan, F. Li, Dynamic pricing for responsive demand to increase distribution network efficiency, Applied energy 205 (2017) 236-243. 
[41] E. Klaassen, R. Van Gerwen, J. Frunt, J. Slootweg, A methodology to assess demand response benefits from a system perspective: A dutch case study, Utilities Policy 44 (2017) 25-37.

[42] J.-Y. Le Boudec, D.-C. Tomozei, Demand response using service curves, in: 2011 2nd IEEE PES International Conference and Exhibition on Innovative Smart Grid Technologies, IEEE, 2011, pp. 1-8.

[43] E. Reihani, M. Motalleb, M. Thornton, R. Ghorbani, A novel approach using flexible scheduling and aggregation to optimize demand response in the developing interactive grid market architecture, Applied energy 183 (2016) 445-455.

[44] Status Review on the Implementation of Distribution System Operators Unbundling Provisions ofthe 3rdEnergy Package. CEER Status Review, CEER, 2016.

[45] P. Larsson, P. Börjesson, Cost models for battery energy storage systems (2018).

[46] Battery energy storage system (bess): A cost/benefit analysis for a pv power station.

URL https://www.nrel.gov/grid/assets/pdfs/second_grid_sim_ zagoras.pdf

[47] A. Ahsan, Q. Zhao, A. M. Khambadkone, M. H. Chia, Dynamic battery operational cost modeling for energy dispatch, in: 2016 IEEE Energy Conversion Congress and Exposition (ECCE), IEEE, 2016, pp. 1-5. 
[48] T. A. Nguyen, M. Crow, Stochastic optimization of renewable-based microgrid operation incorporating battery operating cost, IEEE Transactions on Power Systems 31 (3) (2016) 2289-2296.

[49] C. Zhou, K. Qian, M. Allan, W. Zhou, Modeling of the cost of ev battery wear due to v2g application in power systems, IEEE Transactions on Energy Conversion 26 (4) (2011) 1041-1050.

[50] Y. Yang, N. Yang, H. Li, Cost-benefit study of dispersed battery storage to increase penetration of photovoltaic systems on distribution feeders, in: 2014 IEEE PES General Meeting - Conference \& Exposition, IEEE, 2014, pp. 1-5.

[51] C. A. Correa, A. Gerossier, A. Michiorri, G. Kariniotakis, Optimal scheduling of storage devices in smart buildings including battery cycling, in: 2017 IEEE Manchester PowerTech, IEEE, 2017, pp. 1-6.

[52] B. Marchi, M. Pasetti, S. Zanoni, Life cycle cost analysis for bess optimal sizing, Energy Procedia 113 (2017) 127-134.

[53] J. Choi, H. Jo, S. Han, Bess life span evaluation in terms of battery wear through operation examples of bess for frequency regulation, in: 2017 IEEE Innovative Smart Grid Technologies-Asia (ISGT-Asia), IEEE, 2017, pp. 1-5.

[54] L. Xu, R. Cheng, Z. He, J. Xiao, H. Luo, Dynamic reconfiguration of distribution network containing distributed generation, in: 2016 9th International Symposium on Computational Intelligence and Design (ISCID), Vol. 1, IEEE, 2016, pp. 3-7. 
[55] K.-y. Liu, W. Sheng, Y. Liu, X. Meng, A network reconfiguration method considering data uncertainties in smart distribution networks, Energies 10 (5) (2017) 618.

[56] A. E. Milani, M. R. Haghifam, A new probabilistic approach for distribution network reconfiguration: Applicability to real networks, Mathematical and computer modelling 57 (1-2) (2013) 169-179.

[57] Y.-M. Tzeng, Y.-L. Ke, M.-S. Kang, Generic switching actions of distribution system operation using dynamic programming method, in: 2006 IEEE Industrial and Commercial Power Systems Technical ConferenceConference Record, IEEE, 2006, pp. 1-7.

[58] S. Ghasemi, J. Moshtagh, Radial distribution systems reconfiguration considering power losses cost and damage cost due to power supply interruption of consumers, International Journal on Electrical Engineering and Informatics 5 (3) (2013) 297.

[59] G. Vaskantiras, S. You, Value assessment of distribution network reconfiguration: A danish case study, Energy Procedia 100 (2016) 336-341.

[60] S. Talpur, Dynamic line rating implementation as an approach to handle wind power integration: A feasibility analysis in a sub-transmission system owned by fortum distribution ab (2013).

[61] F. Teng, R. Dupin, A. Michiorri, G. Kariniotakis, Y. Chen, G. Strbac, Understanding the benefits of dynamic line rating under multiple sources of uncertainty, IEEE Transactions on Power Systems 33 (3) (2018) 33063314 . 
[62] M. M. A. El Aziz, D. K. Ibrahim, H. A. Kamel, Estimation of the lifetime of electrical components in distribution networks, The Online Journal on Electronics and Electrical Engineering (OJEEE).

[63] A. Michiorri, P. Taylor, S. Jupe, C. Berry, Investigation into the influence of environmental conditions on power system ratings (2009).

[64] A. Bracale, P. Caramia, P. De Falco, A. Russo, A new procedure to forecast the dynamic rating of buried cables, in: 2018 International Symposium on Power Electronics, Electrical Drives, Automation and Motion (SPEEDAM), IEEE, 2018, pp. 1190-1195.

[65] M. T. Van Genuchten, A closed-form equation for predicting the hydraulic conductivity of unsaturated soils 1, Soil science society of America journal 44 (5) (1980) 892-898.

[66] M. Buhari, V. Levi, S. K. Awadallah, Modelling of ageing distribution cable for replacement planning, IEEE Transactions on Power Systems 31 (5) (2016) 3996-4004.

[67] Percentiles, percentile rank \& percentile range: Definition \& examples. URL https://www.statisticshowto.datasciencecentral.com/ probability-and-statistics/percentiles-rank-range/

[68] Incentives Schemes for Regulating Distribution System Operators, including for innovationA CEER Conclusions Paper, CEER, 2018.

[69] The challenges of grid loss in the regulation of danish distribution system operators. danish energy regulatory authority (dera).

URL http: //www . nordicenergyregulators . org 
[70] H. Cai, S. You, J. Wang, H. W. Bindner, S. Klyapovskiy, Technical assessment of electric heat boosters in low-temperature district heating based on combined heat and power analysis, Energy 150 (2018) 938-949. 
Appendix .1. Initial data

Table AI: Maximum apparent power of electrical loads, assuming $\cos \phi=0.9$

\begin{tabular}{|c|c|c|c|}
\hline \multicolumn{2}{|c|}{ Loop 1} & \multicolumn{2}{|c|}{ Loop 2} \\
\hline $\begin{array}{l}\text { Electrical } \\
\text { load }\end{array}$ & $\begin{array}{c}\text { Max. apparent } \\
\text { power, }[\mathrm{kVA}]\end{array}$ & $\begin{array}{c}\text { Electrical } \\
\text { load }\end{array}$ & $\begin{array}{c}\text { Max. apparent } \\
\text { power, }[\mathrm{kVA}]\end{array}$ \\
\hline 11L1 & 350 & 21L1 & 746 \\
\hline 12L1 & 336 & 21L2 & 739 \\
\hline 13L1 & 430 & 22L1 & 362 \\
\hline 14L1 & 414 & 23L1 & 376 \\
\hline 15L1 & 406 & 24L1 & 276 \\
\hline 16L1 & 874 & 25L1 & 436 \\
\hline 17L1 & 408 & 25L2 & 431 \\
\hline 18L1 & 435 & 26L1 & 421 \\
\hline T19L1 & 85 & T27L1 & 148 \\
\hline T110L1 & 437 & T28L1 & 184 \\
\hline 111L1 & 419 & 29L1 & 328 \\
\hline 112L1 & 413 & 210L1 & 437 \\
\hline 113L1 & 346 & 211L1 & 662 \\
\hline 114L1 & 397 & 212L1 & 50 \\
\hline & & 212L2 & 421 \\
\hline & & 213L1 & 875 \\
\hline & & 214L1 & 378 \\
\hline
\end{tabular}


Table AII: Parameters of the BESS units

\begin{tabular}{c|c|c|c|c} 
BESS & $\begin{array}{c}\text { Apparent } \\
\text { node }\end{array}$ & $\begin{array}{c}\text { Energy, } \\
\text { power, [kVA] }\end{array}$ & $\begin{array}{c}\text { Cost of BESS } \\
\text { [kVh] }]\end{array}$ & $\begin{array}{c}\text { Number of } \\
\text { cycles, [-] }\end{array}$ \\
\hline 1571 & 326 & 326 & 228.2 & 5000 \\
\hline 11371 & 392 & 1176 & 274.4 & 2000 \\
\hline 2671 & 284 & 568 & 198.8 & 3000 \\
\hline 21271 & 346 & 1384 & 242.2 & 5000 \\
\hline 21371 & 381 & 762 & 266.7 & 3000
\end{tabular}




\section{Appendix .2. Forecasting}

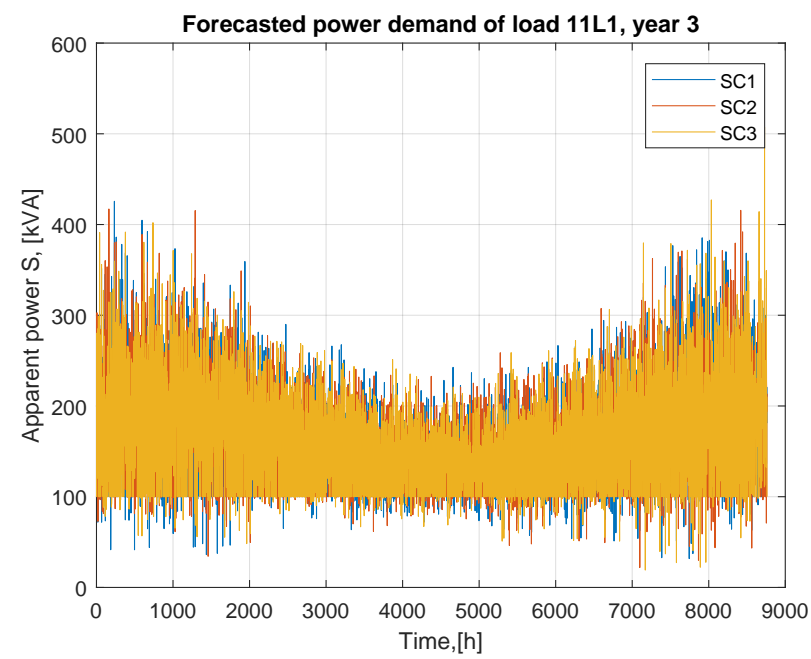

Figure A1: Example of power demand forecast. SC - scenario

\section{Appendix .3. Modelling of cost functions - DLR}

In a traditional operation of distribution networks, the power ratings of overhead lines and cables are considered as fixed values independent of the external conditions. The degree of overloading defined by the coefficient $L$ is typically also set as a constant either for the whole operation period or for a specific season.

However, the exact MCCs of the lines are constantly changing and determined by the ability to dissipate the heat created by an electric current. Dynamically changing MCC based on the external conditions is referred to as DLR. For the cables buried in the soil, DLR is a function of the soil properties, soil temperature, precipitation and cable's burial depth.

By applying DLR in the ADN, a larger degree of overloading could be allowed, thus potentially eliminating CEs. DLR is a FS provided by the 
lines (overhead or cables), which are utility-owned AEs. Similar to RE, DLR can potentially provide medium to long-term reinforcement deferral. The expressions given below are provided for underground cables, with overhead lines covered in [63]. Similar to RE, the potential of DLR in regards to solving congestions at the secondary substations is limited. DLR is best suited to eliminate CEs at the large cables.

\section{Appendix .3.1. CAPEX}

CAPEX of using DLR is generally very low, since DLR is applied to the already existing cables. The main cost included in CAPEX is an installation of the additional equipment - sensors for recording soil temperature, precipitation, etc.

\section{Appendix .3.2. OPEX}

Before estimating the OPEX of applying DLR, the amount of extra capacity provided by DLR has to be determined. This is done by creating a thermal model of the buried cable and determining the cable temperature $T_{C}$, which will affect cable's resistance. The first step is to solve Richards equation to obtain moisture content distribution in time and across all soil layers [64]:

$$
\frac{\partial \theta(t, z)}{\partial t}=\frac{\partial}{\partial z}\left[\delta_{\theta}(t, z) \frac{\partial \theta(t, z)}{\partial z}+k_{\theta}(t, z)\right]
$$

Knowing moisture content, the soil thermal diffusivity $\delta_{T}$ can be found:

$$
\delta_{T}(t, z)=-14.8+0.209 N+4.79 \theta(t, z),
$$

Soil thermal resistivity: 


$$
\rho_{T}(t, z)=\frac{1}{\delta_{T}(t, z) \sigma_{S, d r y} C_{S T}(t, z)},
$$

Eq. A4 shows how the distribution of the soil temperature can be calculated:

$$
\frac{\partial T_{S}(t, z)}{\partial t}=\frac{\partial}{\partial z}\left[\delta_{T}(t, z) \frac{\partial T_{S}(t, z)}{\partial z}\right],
$$

The cable temperature can then be found as follows:

$$
T_{\text {cable }}(t)=T_{S}\left(t, z_{b}\right)+T_{\text {internal }}+\alpha(t) T_{\text {external }}(t),
$$

Using the cable's actual temperature it is possible to estimate DLR using the following expression from [63]:

$$
I_{\text {cable }}(t)=\sqrt{\begin{array}{r}
\frac{\Delta T-q_{d}\left[0.5 R_{T, 1}+n c\left(R_{T, 2}+R_{T, 3}+R_{T}\right)\right]}{r\left(T_{\text {cable }}(t)\right)\left[R_{T, 1}+j\left(1+\lambda_{1}\right) R_{T, 2}+\right.} \\
\left.\left.+n c\left(1+\lambda_{1}+\lambda_{2}\right)\left(R_{T, 3}+R_{T}\right)\right]\right]
\end{array}},
$$

Detailed explanations of how to calculate all the parameters shown above could be found in $[63,64,65]$.

Since in most of the cases using DLR assumes applying higher than rated electrical stresses to the cable, its LT will be reduced because of that. Such reduction can be used to estimate the cost of DLR via cost function $F_{O 1}$, showing the cost of LT's reduction depending on the duration and power required from DLR during CE:

$$
C_{L T_{\text {cable }}}=\frac{C_{\text {cable,total }}}{L T_{\text {cable }, \text { rated }}},
$$


Using Arrhenius model from Eq. A8 [66] the change in the LT of the cable due to the temperature $T_{\text {cable }}$ during $i$ th $\mathrm{CE}$ is estimated, with $T_{\text {cable }}$ is proportional to $I_{\text {cable }}$ and $S_{\text {flex }}$ :

$$
L T_{\text {cable }, D_{\text {flex }, i, s t a r t}}^{\prime}=L T_{\text {cable, rated }} * e^{(-B * T)},
$$

The temperature ratio $T$ is then calculated as:

$$
\begin{gathered}
T=\frac{1}{T_{\text {cable }, i, \text { mean }}}-\frac{1}{T_{\text {cable }, \text { rated }}}, \\
\Delta L T_{\text {cable }, i}^{\prime}=L T_{\text {cable }, D_{\text {flex }, i, s t a r t}}^{\prime}-D_{\text {flex }, i, \text { end }},
\end{gathered}
$$

LT after $i$ th CE referred to the rated temperature $L T_{\text {cable }, D_{\text {flex }, i, e n d}}$ is calculated using Eq. A8 and replacing $L T_{\text {cable,rated }}$ with $\Delta L T_{\text {cable }, i}^{\prime}$. Finally, $\Delta L T_{\text {cable }, i}:$

$$
\Delta L T_{\text {cable }, i}=L T_{\text {cable }, D_{\text {flex }, i, e n d}}-L T_{\text {cable }, D_{\text {flex }, i, \text { start }}}^{\prime},
$$

Using $\Delta L T_{\text {cable }, i}$ and $C_{L T_{\text {cable }}}$ cost function $F_{O 1}$ for DLR is constructed as shown in Fig. A2.

Appendix .4. Example of cost functions for other AE/FS 


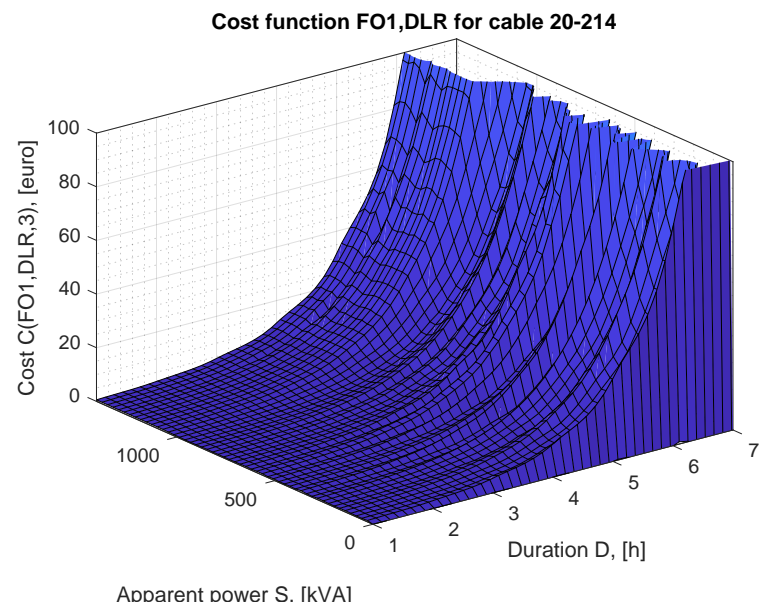

Figure A2: Cost function FO1 for DLR of cable 20-214 in year 3

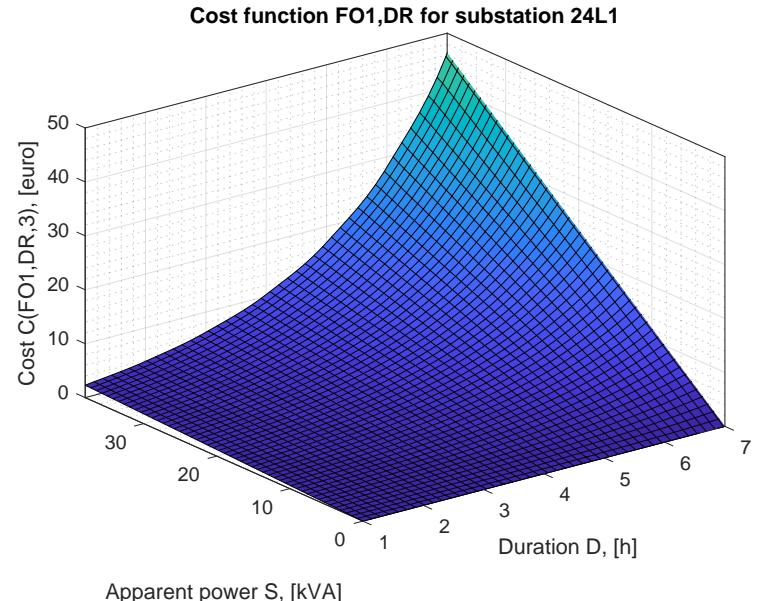

Figure A3: Cost function FO1 for DR at substation 24L1 in year 3 


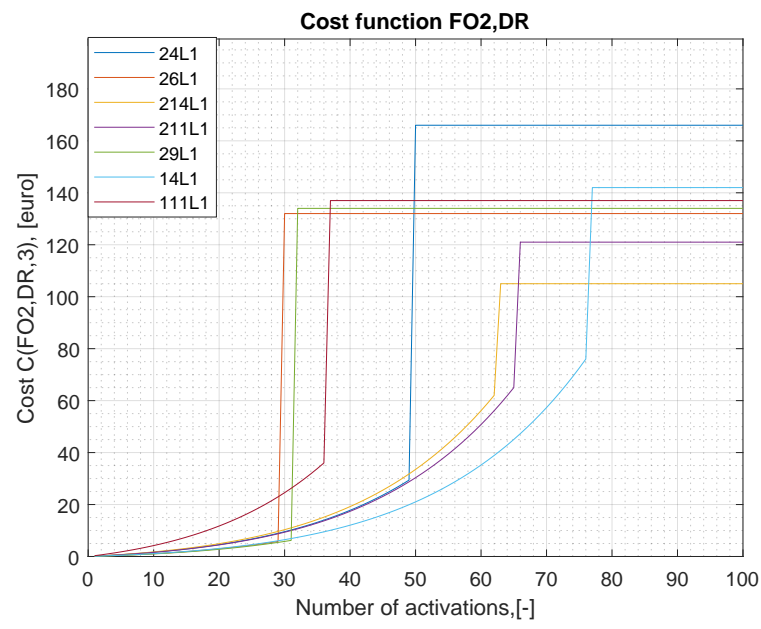

Figure A4: Cost function FO2 for DR in year 3

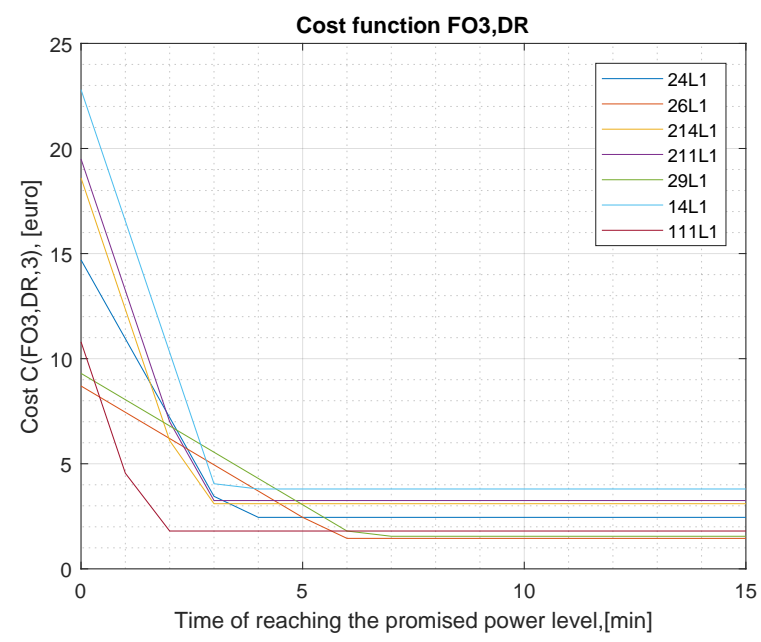

Figure A5: Cost function FO3 for DR in year 3 


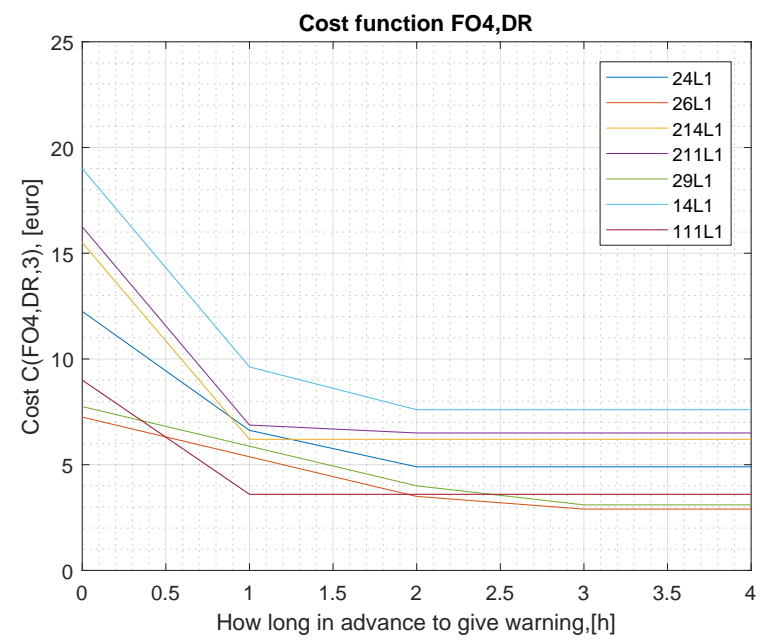

Figure A6: Cost function FO4 for DR in year 3

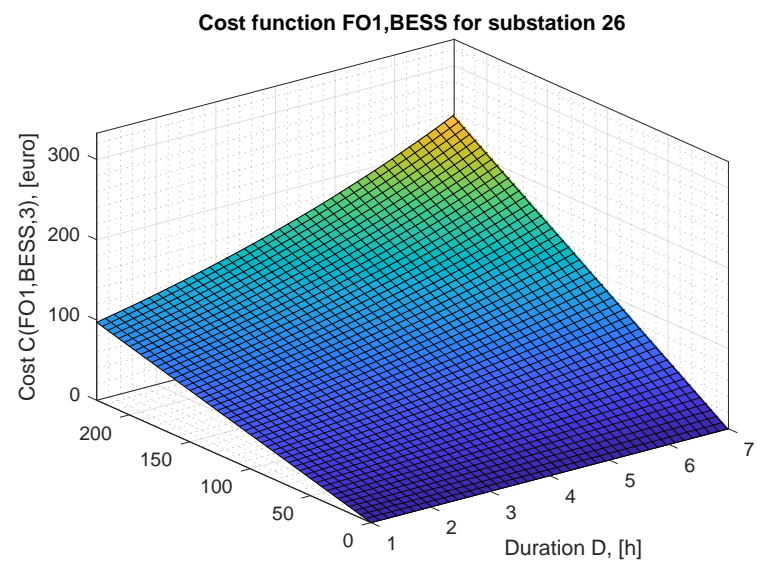

Apparent power S, [kVA]

Figure A7: Cost function FO1 for BESS at substation 26 in year 3 


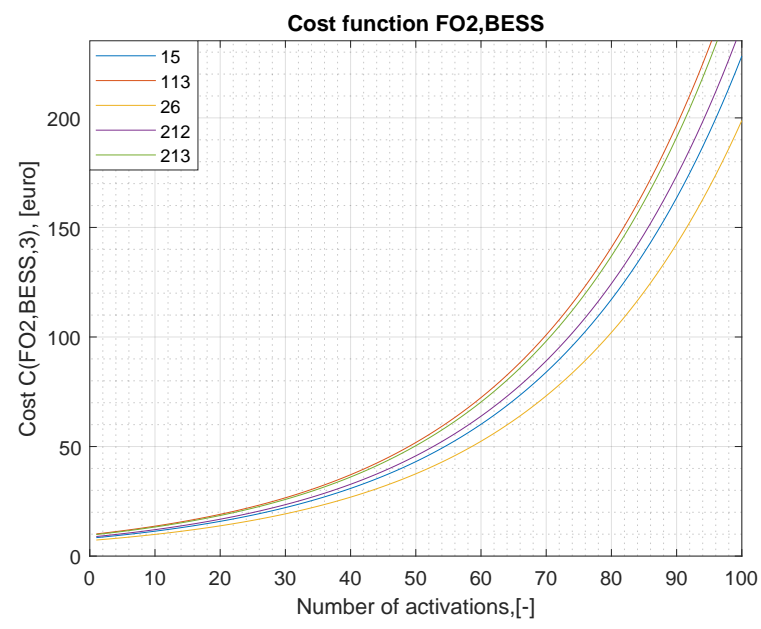

Figure A8: Cost function FO2 for BESS in year 3 